\title{
Modelling and Analysis of the Reliability of a PhotoVoltaic (PV) Inverter
}

\author{
Davoodi, Amirali; Peyghami, Saeed; Yang, Yongheng; Dragicevic, Tomislav; Blaabjerg, Frede
}

\section{Published in:}

Proceedings of 2020 IEEE $11<$ sup >th</sup> International Symposium on Power Electronics for Distributed Generation Systems

Link to article, DOI:

10.1109/PEDG48541.2020.9244471

Publication date:

2020

Document Version

Peer reviewed version

Link back to DTU Orbit

Citation $(A P A)$ :

Davoodi, A., Peyghami, S., Yang, Y., Dragicevic, T., \& Blaabjerg, F. (2020) thodelling and Analysis of the Reliability of a PhotoVoltaic (PV) Inverter. In Proceedings of 2020 IEEE 11 International Symposium on Power Electronics for Distributed Generation Systems (pp. 297-303). IEEE.

https://doi.org/10.1109/PEDG48541.2020.9244471

\section{General rights}

Copyright and moral rights for the publications made accessible in the public portal are retained by the authors and/or other copyright owners and it is a condition of accessing publications that users recognise and abide by the legal requirements associated with these rights.

- Users may download and print one copy of any publication from the public portal for the purpose of private study or research.

- You may not further distribute the material or use it for any profit-making activity or commercial gain

- You may freely distribute the URL identifying the publication in the public portal 
See discussions, stats, and author profiles for this publication at: https://www.researchgate.net/publication/346837779

\section{Modelling and Analysis of the Reliability of a PhotoVoltaic (PV) Inverter}

Conference Paper · September 2020

DOI: 10.1109/PEDG48541.2020.9244471

CITATIONS

0

5 authors, including:

2 Amirali Davoodi

2 Aalborg University

8 PUBLICATIONS 20 CITATIONS

SEE PROFILE

(2) Yongheng Yang

Zhejiang University

419 PUBLICATIONS 6,778 CITATIONS

SEE PROFILE
READS

104

(2.) Saeed Peyghami

65 PUBLICATIONS 639 CITATIONS

SEE PROFILE

Tomislav Dragicevic

Technical University of Denmark

315 PUBLICATIONS 8,622 CITATIONS

SEE PROFILE

Some of the authors of this publication are also working on these related projects:

Hybrid AC/DC Microgrids View project

Project Magnetically Coupled Converter View project 


\title{
Modelling and Analysis of the Reliability of a PhotoVoltaic (PV) Inverter
}

\author{
Amirali Davoodi ${ }^{1}$, Saeed Peyghami ${ }^{1}$, Yongheng Yang ${ }^{1}$, Tomislav Dragičević ${ }^{2}$, and Frede Blaabjerg ${ }^{1}$ \\ ${ }^{1}$ Department of Energy Technology, Aalborg University, Aalborg, Denmark \\ ${ }^{2}$ Department of Electrical Engineering, Technical University of Denmark, Copenhagen, Denmark \\ amirali.davoodi@et.aau.dk
}

\begin{abstract}
In this paper, analytical equations are employed for electro-thermal modelling of a PhotoVoltaic (PV) inverter. This approach results in significantly faster reliability modelling, which is suitable for iterative design and analysis of large-scale systems. Next, considering the mission profiles, reliability metrics of the inverter are extracted for a case study system. Afterwards, the system reliability performance is characterized in terms of input power, switching frequency, and DC-link voltage of the inverter. Subsequently, by using this information, solutions are proposed to improve the inverter reliability and meet the intended requirements. In addition, the impact of the grid on inverter reliability is discussed.
\end{abstract}

Keywords—Reliability, PhotoVoltaic (PV) Inverter, Design for Reliability, Power Electronics.

\section{INTRODUCTION}

The PhotoVoltaic (PV) power generation is growing at a tremendous speed, such that its capacity increased from 41 GW in 2010 to $586 \mathrm{GW}$ in 2019 [1]. In this regard, one of the major challenges facing this booming industry is reliability. Any failure in the system increases the cost of PV energy production by imposing the maintenance cost as well as the loss of energy production during the downtime [2].

On the other hand, power electronic converters are one of the key enabling technologies in the PV systems. Notably, PV inverters can introduce reliability challenges to the system, if not properly designed. For example, loss of approximately 2.3 GWh energy ( $36 \%$ of the total energy lost) was observed in 350 systems operated by SunEdison, over a 27-month period, due to the inverter failures [3].

As a result, inverter reliability modelling is essential to benchmark the system performance and improve the design for higher reliability. However, traditional power electronic reliability modelling methods are mostly based on relibaity handbooks such as MIL-HDBK-217 [4]. For example, in [5], the reliability of a modular multilevel converter is analyzed using this handbook. A similar approach is used in [6] for reliability modelling of a PV inverter. The major drawback of this approach is neglecting the operational conditions and mission profiles. In addition, this method assumes a constant failure rate for the components, which ignores the failures due to the wear-out. To overcome this challenge, in [7], a mission profile-based reliability assessment is carried out on a PV inverter, and the impact of PV array sizing is studied. Interestingly, in [8], an artificial-intelligence-based approach is employed to find the optimal switching frequency and DClink voltage, while minimizing the output filter size. A mission-profile-based approach is also employed for reliability modelling in that paper.

The temperature and its variations play a key role in the lifetime models of capacitors and IGBTs [9]. Therefore, the translation of electrical paramterers to thermal stresses, i.e., electro-thermal modelling, is a significant step in the reliability modelling of the inverter. Typically, to do the

This work was supported by VILLUM FONDEN under the VILLUM Investigators grant for the REPEPS project. electro-thermal modelling, since the experimental data is not available in the design stage, a simulation model is used. In other words, the inverter is simulated for different combinations of solar irradiance and ambient temperature $(S$, $T_{a}$ ). According to the simulation data, a LookUp Table (LUT) is built, which is then used to map every $\left(S, T_{a}\right)$ to component temperature [7]. This approach is time-consuming due to the computational burden of each simulation and the large number of simulations that are needed. Moreover, if any of the system parameters change, the simulation model must be modified, all the simulations must be done again, and the new LUT must be obtained accordingly. Therefore, the LUT and simulation approach might not be practical, particularly for the design and analysis of a large-scale system with a multitude of PV inverters. Hence, in this paper, all the analytical equations required for modelling the $\mathrm{PV}$ power production and calculation of thermal stress of capacitor and IGBTs are presented. The accuracy of the analytical expressions is also compared with the simulation results. It should be noted that such analytical models excel the simulation-based electrothermal modelling in terms of computational efficiency and ease of parameter changing [10]. Thus, the electro-thermal modelling would be faster and more flexible.

Once the thermal stress of the components is obtained, the procedure explained in [11] is followed to acquire the reliability metrics. First, the temperature profiles are converted to the accumulated damage, $D$, by using empirical lifetime models and Miner's rule. Then, the uncertainty of lifetime models and electro-thermal modelling is taken into account by performing a Monte Carlo simulation, where the probability distribution of $D$ is obtained for IGBTs and capacitors. Finally, by using the Reliability Block Diagram (RBD) approach, the inverter reliability is acquired. It is assumed that the reliability of the inverter is expressed using a Weibull distribution with shape and scale parameters of $\beta$ and $\eta$, respectively. $\beta$ and $\eta$ of the inverter are functions of design parameters and mission profiles. Thus, once the reliability model of the system $(\beta$ and $\eta)$ is obtained, iterative design and comparison of various design options would be possible. Since reliability modelling is made faster by using the analytical approach, it can be done for various design parameters and input powers in a short time. By so doing, the relationship between these parameters and the system reliability can be found quickly. These relationships will then be used to improve the reliability and provide guidelines for the reliability-oriented system design, e.g., switching frequency and DC-link voltage selection. Moreover, the reliability of the inverter is characterized as a function of its input power. This characteristic is further used to achieving a certain lifetime by sizing the PV strings and redundancy. In addition, the impact of the grid on the reliability of the inverter is discussed. The rest of the paper is organized as follows. In section II, the analytical expressions for electro-thermal modelling are presented. In section III, the reliability modelling procedure is explained using a case-study inverter, and the analysis of those results are provided. Finally, in section IV, conclusions are drawn. 


\section{EleCtro-Thermal ModELling}

The schematics of the understudy PV system is illustrated in Fig. 1. The focus of this paper will be on the inverter reliability. As mentioned before, temperature and its fluctuations have a considerable role in the lifetime model of IGBTs and capacitors. Therefore, in this section, analytical equations are employed to calculate the IGBT junction temperature, $T_{j}$, and capacitor hotspot temperature, $T_{h}$.

\section{A. PV panel modelling}

The input power of the inverter is the power produced by PV panels. The maximum extractable power from the panels varies during the day for different values of solar irradiance, $S$, and temperature, $T$. The goal of this part is to obtain the PV output power at the maximum power point, i.e., $P_{m p p t}$, as a function of $S$ and $T$. To do so, the single-diode equivalent circuit [12] is selected for the panel as shown in Fig. 2. In this circuit, $R_{s}$ is the series resistance, $R_{s h}$ is the shunt resistance, and $I_{i r r}$ is the photo-generated current.

The parameters of the single-diode model, as well as $n$ (diode ideality factor) and $I_{0}$ (dark saturation current), can be calculated in terms of solar irradiance, temperature, and datasheet parameters using the following equations [12]-[14]:

$$
\begin{gathered}
n=\frac{2 V_{m p}-V_{o c}}{N_{s} V_{t} \ln \left(1-I_{m p} / I_{s c}\right)}\left[1-I_{m p}\right. \\
\frac{\left(I_{s c}-I_{m p}\right)\left(\ln \left(1-I_{m p} / I_{s c}\right)+\left(I_{m p} /\left(I_{s c}-I_{m p}\right)\right)\right.}{R_{s}}=\frac{V_{o c}-V_{m p}+N_{s} n V_{t} \ln \left(1-I_{m p} / I_{s c}\right)}{I_{m p}} \\
R_{s h}=\left(\frac{S_{r e f}}{S}\right) \frac{\left(V_{m p}-I_{m p} R_{s}\right)\left(R_{s}\left(I_{s c}-I_{m p}\right)-V_{m p}+N_{s} n V_{t}\right)}{I_{m p}\left(N_{s} n V_{t}+I_{s c} R_{s}-I_{m p} R_{s}+V_{m p}\right)-I_{s c} V_{m p}} \\
I_{i r r}=\frac{S}{S_{r e f}} k_{p h}\left[I_{s c}\left(1+S_{r e f} R_{s} / S R_{s h}\right)+T C_{s c}\left(T-T_{r e f}\right)\right] \\
\left.I_{0}=\frac{I_{s c}-I_{m p}+S_{r e f}\left(I_{s c} R_{s}-V_{m p}-I_{m p} R_{s}\right) / S R_{s h}}{\exp \left(\left(V_{m p}+I_{m p} R_{s}\right) /\left(N_{s} n V_{t}\right)\right)}\right)_{T_{r e f}} . \exp \left(\frac{q E_{g}}{n k_{B}}\left(\frac{1}{T}-\frac{1}{T_{r e f}}\right)\right)
\end{gathered}
$$

In the datasheet of PV panels, the following parameters are provided for a standard test condition (i.e., at a reference solar irradiance and temperature, $S_{r e f}$ and $T_{r e f}$ ): $V_{m p}$ (maximum power voltage), $I_{m p}$ (maximum power current), $V_{o c}$ (opencircuit voltage), $I_{s c}$ (short-circuit current), $N_{s}$ (number of cells), and $T C_{s c}$ (temperature coefficient of short-circuit current). Notably, $k_{B}=1.380 \times 10^{-23}\left(\mathrm{~J} /{ }^{\circ} \mathrm{K}\right)$ is the Boltzmann's constant, $k_{p h}$ is the spectral factor and is equal to 1 for air mass ratio of $1.5[14], q=1.602 \times 10^{-19}(\mathrm{C})$ is the elementary charge, and all the temperatures must be in Kelvin. Moreover, thermal voltage is $V_{t}=k_{B} T q^{-1}$, and the energy bandgap of the material is $E_{\mathrm{g}}=1.17-4.73 \times 10^{-3} \times T^{2} \times(T+636)^{-1}$ [14]. Finally, the

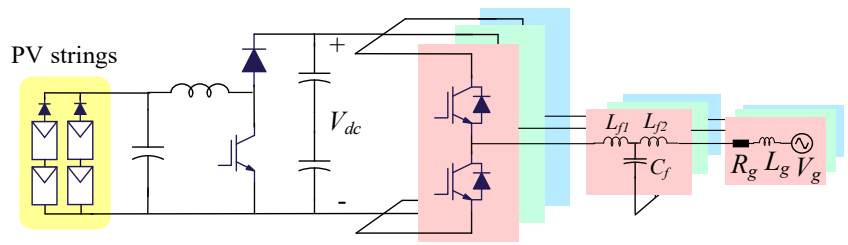

Fig. 1. Schematic of the PV system.

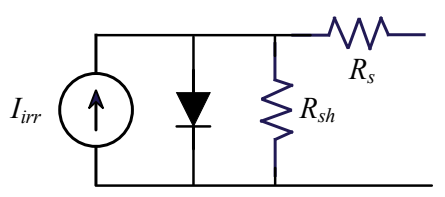

Fig. 2: Single-diode model of the PV cell.

output power of the PV panel at the maximum power point, i.e., $P_{m p p t}$, can be expressed in terms of aforementioned parameters (which themselves are functions of $S$ and $T$ ) as:

$$
\begin{gathered}
V_{m p p t}=\left[-1+W\left(\frac{I_{i r r}+I_{0}}{I_{0}} e^{1}\right)\right]\left[N_{s} n V_{t}\left(1+\frac{R_{s}}{R_{s h}}\right)-\right. \\
\left.R_{s} I_{0} \exp \left(-1+W\left(\frac{I_{i r r}+I_{0}}{I_{0}} e^{1}\right)\right)\right] \\
P_{m p p t}=V_{m p p t}\left[-1+W\left(\frac{I_{i r r}+I_{0}}{I_{0}} e^{1}\right)\right] . \\
.\left[I_{0} \exp \left(-1+W\left(\frac{I_{i r r}+I_{0}}{I_{0}} e^{1}\right)\right)-\frac{N_{s} n V_{t}}{R_{s h}}\right]
\end{gathered}
$$

where $W$ is the Lambert-W function [13].

\section{B. Grid and LCL filter modelling}

It is assumed that the inverter is connected to the grid through an LCL filter, as shown in Fig. 3, and the power factor of the current injected to the grid-side terminals is 1 .

The RMS value of phase voltage $\left(V_{i}\right)$, current $\left(I_{i}\right)$, and the power factor $\left(\cos \varphi_{i}\right)$, at the inverter-side terminals (before filter), can be calculated as:

$$
\begin{aligned}
& V_{g t}=\sqrt{\left(P R_{g}+\frac{V_{g}^{2}}{2}\right)+\sqrt{\left(P R_{g}+\frac{V_{g}^{2}}{2}\right)^{2}-Z_{g}^{2} P^{2}}} \\
& V_{i}^{2}=V_{g t}^{2}\left(1-L_{1 f} C_{f} \omega_{g}{ }^{2}\right)^{2}+ \\
& \left(\omega_{g}\left(L_{1 f}+L_{2 f}\right) I_{g}-L_{1 f} L_{2 f} C_{f} I_{g} \omega_{g}^{3}\right)^{2} \\
& I_{i}^{2}=I_{g}{ }^{2}\left(1-L_{2 f} C_{f} \omega_{g}{ }^{2}\right)^{2}+\left(V_{g t} C_{f} \omega_{g}\right)^{2} \\
& \cos \varphi_{i}=\cos \left[\tan ^{-1}\left(\frac{\omega_{g}\left(L_{1 f}+L_{2 f}\right) I_{g}-L_{1 f} L_{2 f} C_{f} I_{g} \omega_{g}{ }^{3}}{V_{g t}\left(1-L_{1 f} C_{f} \omega_{g}{ }^{2}\right)}\right)\right. \\
& \left.-\tan ^{-1}\left(\frac{V_{g t} C_{f} \omega_{g}}{I_{g}\left(1-L_{2 f} C_{f} \omega_{g}{ }^{2}\right)}\right)\right]
\end{aligned}
$$

where $P=P_{\text {mppt }} / 3, I_{g}=P / V_{g t}$. Also, $L_{1 f}, L_{2 f}$, and $C_{f}$ are filter parameters, $\omega_{g}$ and $V_{g}$ are the angular frequency and RMS value of the grid phase voltage, respectively. Also, the grid impedance is given from $Z_{g}{ }^{2}=R_{g}{ }^{2}+\left(\omega_{g} L_{\mathrm{g}}\right)^{2}$, in which $R_{g}$ and $L_{g}$ are the grid resistance and inductance.

\section{IGBT electro-thermal modelling:}

As shown in Fig. 4, the junction temperature of the IGBT in the inverter is composed of two components, an average term, $T_{j m}$, and line-frequency fluctuations, $\Delta T_{j}[8]$.

Concerning the thermal model of the IGBT, an Nth-order Foster network is selected, as shown in Fig. 5. The values for each layer of Foster network, $R_{t h}$ and $\tau_{t h}$, are directly provided

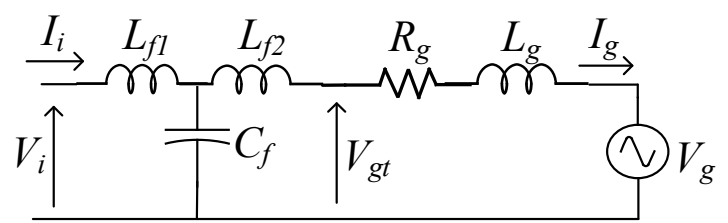

Fig. 3. Equivalent circuit of the LCL filter and grid. 


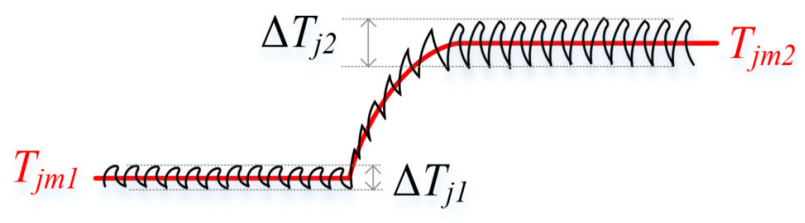

Fig. 4. The junction temperature of an IGBT.

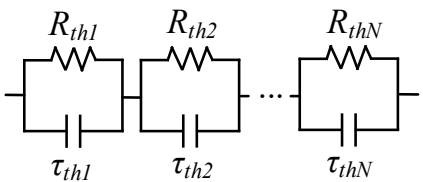

Fig. 5. N-th order thermal Foster network.

in some datasheets. If not, they can be obtained by curvefitting on the thermal impedance curve given in datasheets. According to Fig. 5, the equivalent thermal resistance, $R_{t h, e q}$, and line-frequency impedance, $Z_{t h, e q}$, can be calculated as:

$$
\begin{gathered}
R_{t h_{e q}}=\sum_{n=1}^{N} R_{t h_{n}} \\
Z_{t h_{e q}}=\left|\sum_{n=1}^{N} \frac{R_{t h_{n}}}{1+\omega^{2}{ }_{g} \tau^{2}{ }_{t h_{n}}}-j \sum_{n=1}^{N} \frac{R_{t h_{n}} \omega^{2}{ }_{g} \tau^{2}{ }_{t h_{n}}}{1+\omega^{2}{ }_{g} \tau^{2}{ }_{t h_{n}}}\right|
\end{gathered}
$$

where $\omega_{g}$ is the grid angular frequency.

Given the space vector modulation, the $T_{j m}$ and delta $T_{j}$ (refer to Fig. 4) can be calculated as [15]:

$$
\begin{gathered}
A=\frac{1}{2 \pi}+\frac{m_{a} \cos \varphi_{i}}{8} \\
B=\frac{1}{8}+\frac{m_{a} \cos \varphi_{i}}{3 \pi}+\frac{3 m_{a}}{8 \pi^{2}} \sin ^{2} \varphi_{i}+\frac{m_{a}}{48}-\frac{3 m_{a}}{4}\left(\frac{\varphi_{i}}{\pi}\right)^{2}-\frac{3 m_{a}}{8 \pi^{2}} \\
C=f_{s w} E_{s w @ T_{r e f}} \sqrt{2} \frac{I_{i}}{I_{r e f}}\left(\frac{V_{d c}}{V_{r e f}}\right)^{K_{v}} \\
D=\sqrt{2} R_{t h_{e q}} A I_{i}\left(v_{c e 0 @ T_{r e f}}-\alpha_{v_{c e 0}} T_{r e f}\right)+ \\
2 R_{t h_{e q}} B I_{i}^{2}\left(r_{c e @ T_{r e f}}-\alpha_{r_{c e}} T_{r e f}\right)+R_{t h_{e q}} C\left(1-\alpha_{E_{s w}} T_{r e f}\right)+T_{a} \\
E=1-\sqrt{2} R_{t h_{e q}} A I_{i} \alpha_{v_{c e}}-2 R_{t h_{e q}} B I_{i}^{2} \alpha_{r_{c e}}-R_{t h_{e q}} C \alpha_{E_{s w}} \\
T_{j m}=\frac{D}{E} \\
\Delta T_{j}=\pi\left(T_{j m}-T_{a}\right) \frac{Z_{t h_{e q}}}{R_{t h_{e q}}}
\end{gathered}
$$

where $f_{s w}$ and $V_{d c}$ are switching frequency and DC-link voltage, $m_{a}=2 \sqrt{2} V_{i} / V_{d c}$ is the modulation index, and $V_{i}, \varphi_{i}$, and $I_{i}$ are given from (9), (10), and (11). $K_{v}$ can be selected between 1.3 and 1.4. Also, $T_{a}$ is the ambient temperature, and $R_{t h, e q}$ and $Z_{t h, e q}$ are given from (12) and (13). The values of $r_{c e}$, on-state bulk resistance, $v_{c e 0}$, threshold voltage, $E_{s w}$, switching losses are given in the datasheet of IGBT, for a reference collector-emmiter volateg, $V_{\text {ref }}$, and collector current, $I_{r e f}$, for different temperatures, including $T_{\text {ref }}$ (or can be obtained from the provided curves). $\alpha_{X}$ is the temperature coefficient of variable $X\left(X\right.$ can be $r_{c e}, v_{c e}$, and $\left.E_{s w}\right)$, which can be calculated as:

$$
\alpha_{X}=\frac{X_{@ T_{2}}-X_{@ T r e f}}{T_{2}-T_{r e f}}
$$

where $T_{2}$ is another temperature, for which the value of $X$ is known.

\section{Capacitor electro-thermal modelling}

In Fig. 6, $k_{f}=E S R_{@ \mathrm{f}(\mathrm{Hz})} / \mathrm{ESR}_{@ 100(\mathrm{~Hz})}$ of the capacitor ECSJ2CU681M is shown, where ESR is the Equivalent Series Resistance. As can be concluded from Fig. 6, the value of the ESR decreases monotonically as the frequency increases, until it reaches the $f_{h}$. After $f_{h}$, the variation in $k_{f}$ is negligible, and it can be approximated with $k_{f h}$. In addition, given the space vector modulation and the unity power factor, the capacitor current will only contain inverter switching frequency harmonics[16]. Therefore, if the inverter switching frequency is larger than $f_{h}$, the hotspot temperature of the capacitor can be calculated according to [16]:

$$
\begin{aligned}
& T_{h}=T_{a}+2 R_{t h_{C}} k_{f h} E S R_{@ 100 H z} I_{i}^{2} m_{a} . \\
& .\left(\frac{\sqrt{3}}{4 \pi}+\cos ^{2} \varphi_{i}\left(\frac{\sqrt{3}}{\pi}-9 \frac{m_{a}}{16}\right)\right)
\end{aligned}
$$

where $m_{a}$ is the modulation index, $I_{i}$ and $\varphi_{i}$ are given from (10) and (11), Rthc is the thermal resistance of the capacitor, and $E S R_{@ 1100 \mathrm{~Hz}}$ as well as $k_{f h}=E S R_{@ f h(\mathrm{~Hz})} / E S R_{@ 100(\mathrm{~Hz})}$ can be found in some capacitor datasheets.

\section{E. Comparison with simulation results}

Based on the system shown in Fig. 1, a simulation model was built to compare the analytical results of $T_{h}, T_{j}$, and $\Delta T_{j}$, with simulation results.

Inverter and filter parameters are given in Table I. Also, grid parameters are presented in Table II. BP365 $65 \mathrm{~W}$ is selected as the PV panel, whose specification can be found in [17]. In each PV string, the number of series-connected panels and parallel branches are 20 and 3, respectively. The strings configuration is also shown in Fig. 1. F3L25R12W1T4_B27 and ECSJ2CU681M are selected as IGBT modules and DClink capacitors, respectively.

At $T_{a}=25^{\circ} \mathrm{C}$, the junction temperature of the IGBT (mean, $T_{j}$, and line-frequency variations, $\Delta T_{j}$ ) is obtained using simulation and analytical expressions, and shown in Fig 7. Similarly, the hotspot temperature of the capacitor is acquired using simulation and analytical expressions. The comparison of these results can be seen in Fig. 8. As it can be seen from Fig. 7 and Fig. 8, the analytical electro-thermal approach can give acceptable results comparing to simulationbased electro-thermal modelling. However, it should be noted that the computational efficiency of the analytical approach outperforms that of the simulation-based approach.

TABLE I. INVERTER PARAMETERS For THE SySTEM SHOWN IN FIG. 1

\begin{tabular}{cc}
\hline Parameter & Value \\
\hline$V_{d c}$ & $800(\mathrm{~V})$ \\
\hline$f_{s w}$ & $2500(\mathrm{~Hz})$ \\
\hline$L_{1 f}$ & $3.5(\mathrm{mH})$ \\
\hline$L_{2 f}$ & $0.5(\mathrm{mH})$ \\
\hline$C_{f}$ & $22(\mu \mathrm{F})$ \\
\hline
\end{tabular}

TABLE II. GRID PARAMETERS FOR THE SYSTEM SHOWN IN FIG. 1

\begin{tabular}{cc}
\hline Parameter & Value \\
\hline$V_{g}$ & $230(\mathrm{~V})$ \\
\hline$f_{g}$ & $50(\mathrm{~Hz})$ \\
\hline$R_{g}$ & $0.5(\Omega)$ \\
\hline$L_{g}$ & $1(\mathrm{mH})$ \\
\hline
\end{tabular}




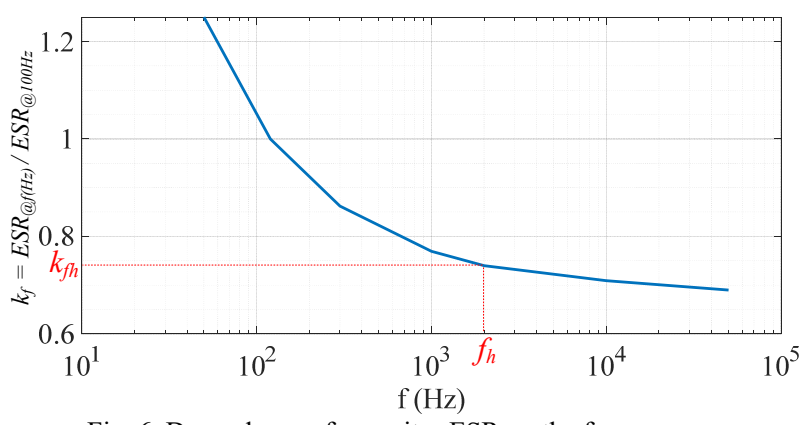

Fig. 6. Dependence of capacitor ESR on the frequency.

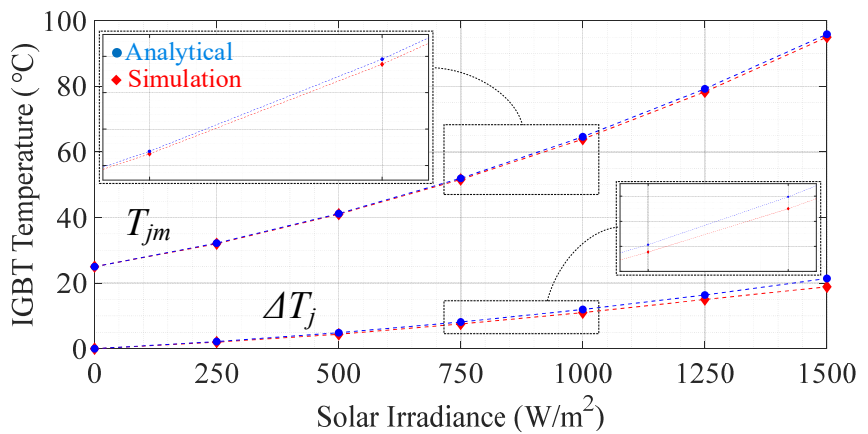

Fig. 7. Comparison of analytical and simulation results for the IGBT junction temperature.

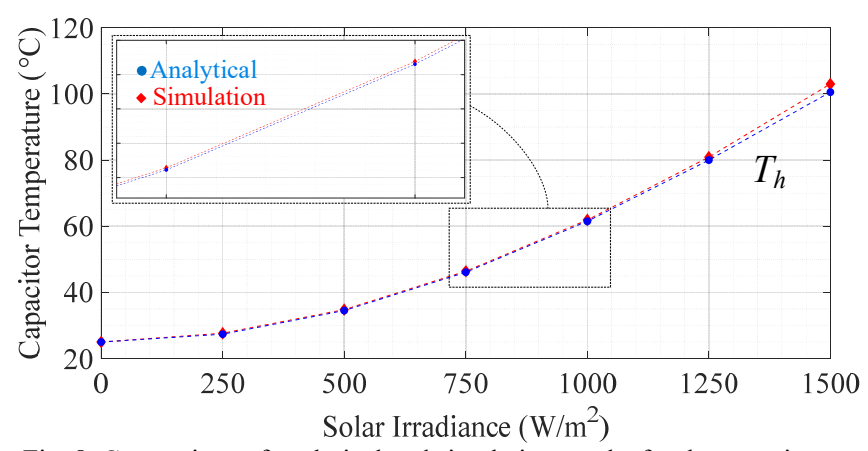

Fig. 8. Comparison of analytical and simulation results for the capacitor hotspot temperature.

\section{RELIABILITY MODELLING AND ANALYSIS}

\section{A. Modelling}

The yearly mission profile (solar irradiance and ambient temperature) in Aalborg is shown in Fig. 9. By using the analytical expressions presented in the last section, the mission profiles can be translated into IGBT and capacitor temperature profiles, as shown in Fig. 10. By applying the rainflow counting algorithm [11] to the IGBT temperature profile, they can be classified into $K$ different cycles, with associated temperature swing $\left(\Delta T_{j}\right)$, average temperature $\left(T_{m}\right)$, on-time $\left(t_{o n}\right)$, and the number of occurrences of each cycle $(n)$. For the line-frequency variations, temperature swing, on-time, and the number of cycles are known. The lifetime model of IGBT is expressed in terms of the number of cycles to failure, $N_{f}$, as:

$$
N_{f}=A \Delta T_{j}^{\beta_{1}} \exp \left(\frac{\beta_{2}}{T_{j \max }+273}\right)\left(\frac{t_{\text {on }}}{1.5}\right)^{\beta_{3}}
$$

where $\Delta T_{j}$ and $T_{j \max }$ are the ripple and maximum of the junction temperature in the cycle, respectively, and $t_{o n}$ is the on-time of the cycle. $A, \beta_{1}, \beta_{2}$, and $\beta_{3}$ are lifetime parameters
TABLE III. PARAmeters OF THE IGBT Module LifETIME Model

\begin{tabular}{cc}
\hline Lifetime parameter & Value \\
\hline$A$ & $8.3255 \times 10^{14}$ \\
\hline$\beta_{1}$ & -7.01 \\
\hline$\beta_{2}$ & 2553 \\
\hline$\beta_{3}$ & -0.3 \\
\hline
\end{tabular}

presented in Table III, extracted from curve-fitting on data provided in [18]).

The accumulated damage to the IGBT can be calculated according to Miner's rule as [11]:

$$
D_{I G B T}=\sum_{i=1}^{K} \frac{n_{i}}{N_{f i}}
$$

where $K$ is the total number of cycles, and for the cycle $i, N_{f i}$ and $n_{i}$ are obtained from (23) and rainflow counting algorithm (as explained above), respectively. It is worth mentioning that the accumulated damage, $D$, indicates what proportion of the lifetime of the device is consumed.

Similarly, the lifetime of an electrolytic capacitor, for a given hotspot temperature, $T_{h}$, and operating voltage, $V$, can be calculated as:

$$
L=L_{r e f} \cdot 2^{\frac{T_{h, r e f}-T_{h}}{n_{1}}} \cdot\left(\frac{V}{V_{r e f}}\right)^{-n_{2}}
$$

where $L_{r e f}$ is the rated lifetime of the capacitor under the reference hotspot temperature, $T_{h, r e f}$, and rated voltage, $V_{r e f}$.

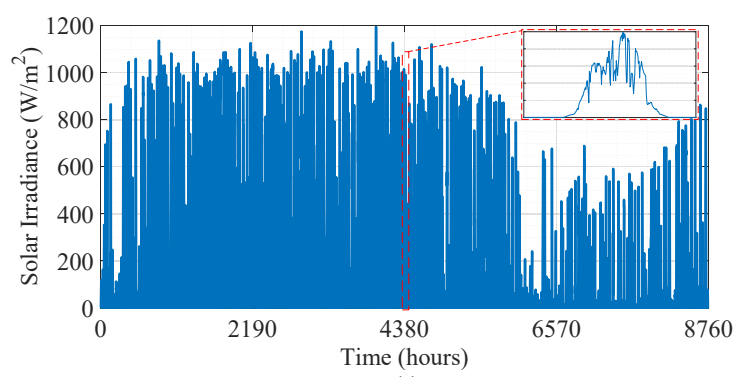

(a)

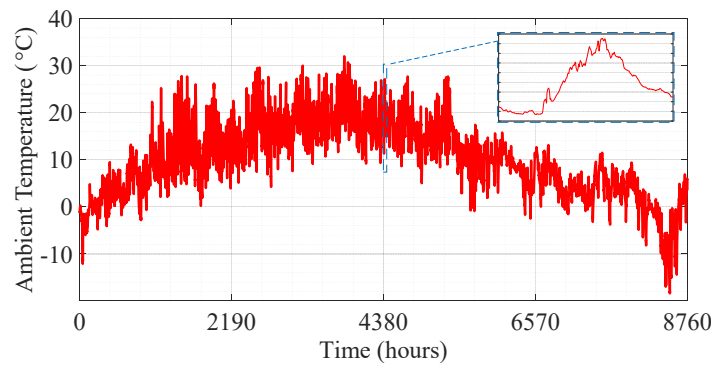

(b)

Fig. 9. Mission profile for Aalborg: (a) solar irradiance and (b) ambient temperature.

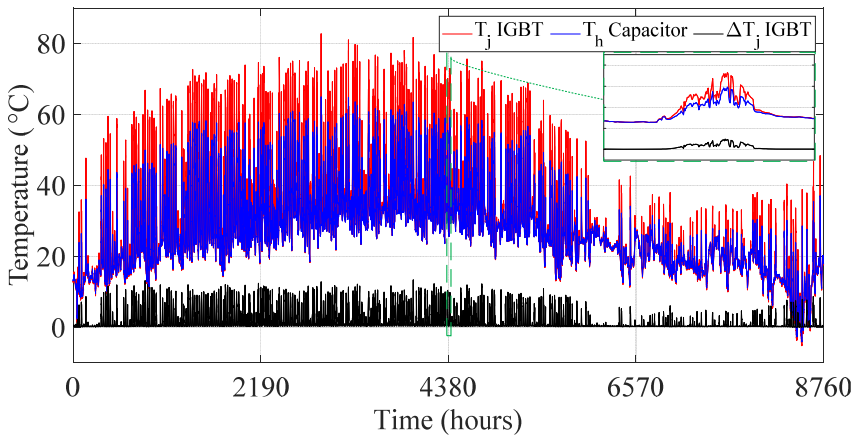

Fig. 10. Temperature profiles: $T_{j}$ (red) and $\Delta T_{j}$ (black) for IGBTs, and $T_{h}$ (blue) for capacitors. 
TABLE IV. PARAMETERS FOR THE CAPACITOR LIFETIME MODEL

\begin{tabular}{cc}
\hline Parameter & Value \\
\hline$L_{r e f}$ & 7000 (hours) \\
\hline$T_{r e f}$ & $105^{\circ} \mathrm{C}$ \\
\hline$n_{1}$ & 10 \\
\hline$n_{2}$ & 2.5
\end{tabular}

The parameters $n_{1}$ and $n_{2}$ are presented in Table IV from the data provided in [19].

The hotspot temperature profile is then classified into $M$ different temperature levels. The accumulated damage to the capacitor is finally calculated as:

$$
D_{\text {cap }}=\sum_{i=1}^{M} \frac{t_{i}}{L_{i}}
$$

in which, for the temperature level $i, L_{i}$ is obtained from (25), and $t_{i}$ is the number of hours that the temperature level $i$ happens.

Due to the manufacturing process, tolerance of component values, there is inherent uncertainty in the resulted temperature values. Also, lifetime parameters are the result of experimental tests on a limited number of components. Therefore, there is uncertainty for the lifetime model parameter. To take all these uncertainties into account, it is assumed that these factors, i.e., lifetime model parameter and temperatures, follow a normal distribution which experiences $5 \%$ variations around their static value. By this assumption, a distribution will be acquired for the damage, $D$, which can be obtained by performing a Monte Carlo simulation. Based on the damage, since the lifetime is $D^{-1}$, the reliability function of the component, $R(t)$, can be acquired. Since there are six IGBTs in the module and two capacitors in the DC-link, according to the reliability block diagram approach, the reliability function of the inverter, $R_{i n v}(t)$ can be expressed as:

$$
R_{\text {inv }}(t)=R_{I G B T}^{6}(t) \cdot R_{\text {Cap }}^{2}(t)
$$

in terms of reliability of each IGBT and capacitor, $R_{I G B T}(t)$ and $R_{\text {Cap }}(t)$, respectively. By performing a 10000-sample Monte Carlo simulation, the distribution of the damage to IGBTs and capacitors was obtained, which is shown in Fig. 11. Accordingly, the reliability function of the inverter is calculated and presented in Fig. 12. Finally, the inverter reliability function is approximated with a Weibull distribution with the shape and scale parameters of $\beta$ and $\eta$.

\section{B. Analysis}

Different reliability metrics, e.g., $B_{1}, B_{10}$, or $M T T F$, can be used as decision-making criteria at different levels. $B_{X}$ lifetime is the number of years in which $X \%$ of the inverters fail, and $M T T F$ is the average time to failure of the inverters. $\beta$ and $\eta$ can be translated to these metrics using the following equations:

$$
\begin{gathered}
B_{X}=\eta \sqrt[\beta]{\ln \left(\frac{1}{1-X / 100}\right)} \\
M T T F=\eta \Gamma\left(1+\frac{1}{\beta}\right)
\end{gathered}
$$

where $\Gamma$ is the gamma function.

For the case study inverter, $(\beta, \eta), B_{1}, B_{10}$, and MTTF are given in Table V. Typically, the lifetime of PV panels is 25 years. Therefore, if the $B_{10}=25$ years is required as the decision making criteria, the case study inverter fails to meet

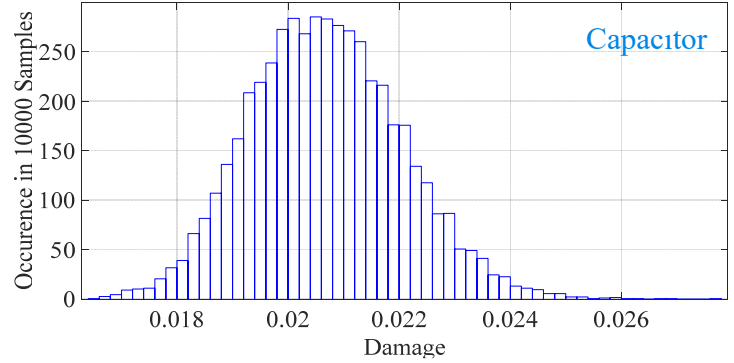

(a)

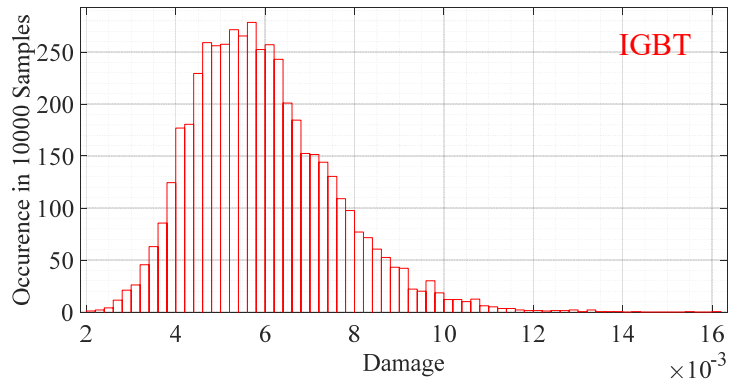

(b)

Fig. 11. The distribution of damage to: (a) capacitor and (b) IGBT

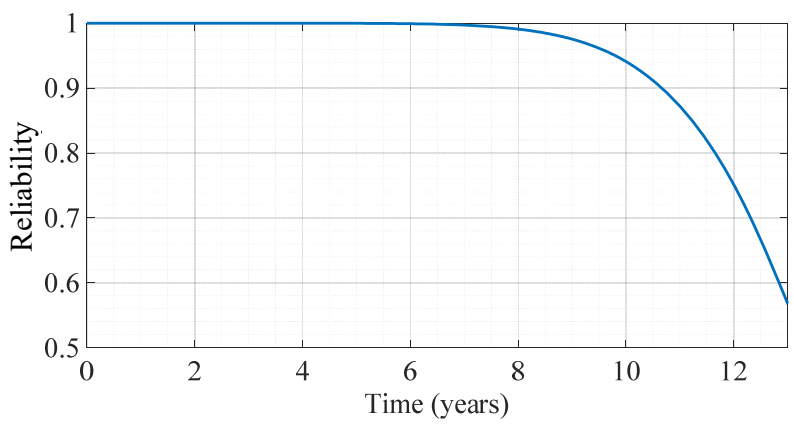

Fig. 12. Reliability function of the inverter.

this requirement. Hence, it is necessary to revise the design so that the reliability requirement is reached. To do so, $B_{10}$ lifetime values are calculated in terms of different parameters, and the results are analyzed here.

Input power: To a great extent, the reliability of the inverter depends on its input power. The annual profile of inverter rated input power, $P_{\text {in,rated }}$, is given in Fig. 13. Given that the inverter input power is multiplied by $k_{p}$, i.e., $k_{p}=P_{\text {in }}$ $/ P_{\text {in,rated }}$, the $B_{10}$ lifetime of the inverter is calculated for different values of $k_{p}$ and shown in Fig. 14. If a certain $B_{10}$ is required, the value of $k_{p}$ can be found using this figure. For example, for $B_{10}=25$ years, according to Fig. $14, k_{p}=0.82$ must be selected. In other words, the inverter must be derated to $82 \%$ of rated input power. This can be achieved by changing the total number of PV panels in the strings from 240 to 196. Alternatively, using 52-Watt panels, rather than the current 65-Watt panels, can result in $B_{10}=25$ years. Interestingly, $k_{p}=0.5$ is the case where two reductant inverter are used in parallel to process the input power. Consequently,

TABLE V. RELIABILITY METRICS OF THE CASE STUDY INVERTER

\begin{tabular}{cc}
\hline Reliability metric & Value \\
\hline$(\beta, \eta)$ & $(8.5,13.9)$ \\
\hline$B_{1}$ & 8.1 years \\
\hline$B_{10}$ & 10.7 years \\
\hline$M T T F$ & 13.14 years
\end{tabular}


for the case where two redundant inverters are used, the $B_{10}$ lifetime of the inverter changes from around 10 years to more than 45 years, which shows the significance of redundancy in reliability improvement.

Switching frequency and DC-link voltage: As can be seen from Fig. 15, the $B_{10}$ lifetime of the converter decreases as the switching frequency, $f_{s w}$, increases. This can be justified by the fact that the switching loss of the IGBT is directly proportional to the $f_{s w}$. So, from the reliability point of view, the smallest possible $f_{s w}$ must be selected. However, the value of filter inductors, $L_{f 1}$ and $L_{f 2}$, increases when a small $f_{s w}$ is selected, which leads to extra cost and size.

As for the DC-link voltage, $V_{d c}$, for each switching frequency, as shown in Fig. 15, the lifetime of the converter increases, as $V_{d c}$ increases, until it reaches a maximum value. $V_{d c, \text { opt }}$ is the value of optimal DC-link voltage which yields the maximum lifetime. If $V_{d c}$ increases more than $V_{d c \text {,opt }}$, the lifetime begins to decrease. This behavior can be justified by the fact that the IGBT conduction loss is a function of modulation index, which is proportional to $1 / V_{d c}$. In contrast, switching losses is directly proportional to $V_{d c}$. As a result, an increase of $V_{d c}$ leads to the decrease of conduction loss and increase of switching loss. Therefore, there is an optimal value for $V_{d c}$, where the total losses is minimum, and the lifetime is maximum. The trajectory of maximum lifetime and $V_{d c \text {,opt }}$ is shown with dashed black line in Fig. 15. As can be seen in this figure, the value of $V_{d c \text {,opt }}$ increases as $f_{s w}$ decreases. The relationship between $f_{s w}$ and $V_{d c, o p t}$ is shown in Fig. 16.

As it can be concluded from Fig. $15, B_{10}=25$ years cannot be achieved for $f_{s w}>1500 \mathrm{~Hz}$. However, the voltage rating of the IGBTs must also be noticed while designing the system which is $1200 \mathrm{~V}$ in this case. It is also worth mentioning that for a certain $B_{10}$ value, the maximum lifetime trajectory (dashed black line in Fig. 15) gives the highest $f_{s w}$, which may result in the filter size reduction. In other words, the intersection of the horizontal line of the required $B_{10}$ with the maximum lifetime trajectory (dashed black line) gives the

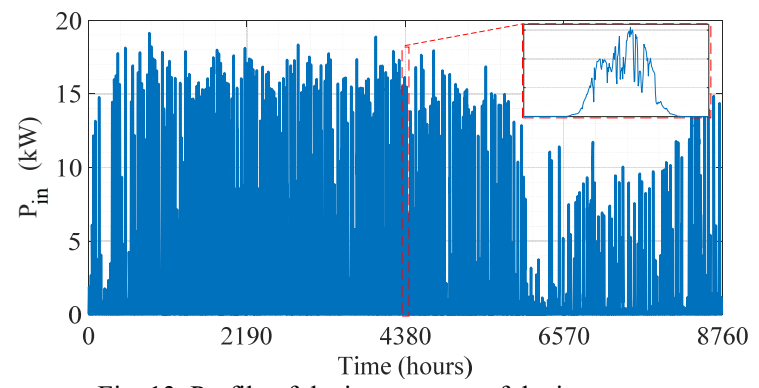

Fig. 13. Profile of the input power of the inverter.

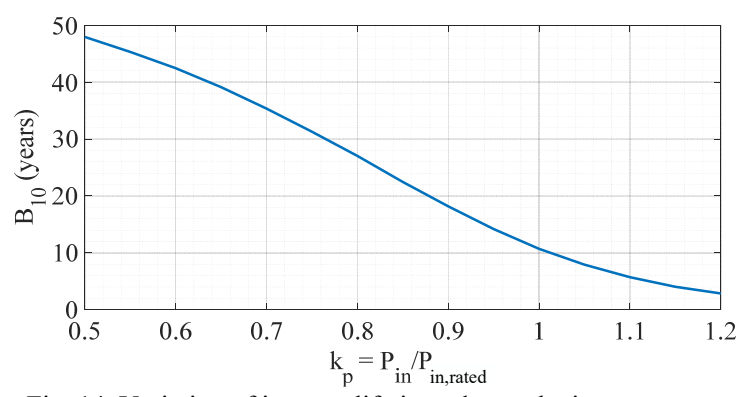

Fig. 14. Variation of inverter lifetime, due to the input power. value of $V_{d c, o p t}$. The value of $f_{s w}$ which is found from Fig. 16, is the maximum switching frequency that can result in the intended $B_{10}$.

Impact of grid on the inverter reliability: The grid impedance influences the stress on the inverter, and thereby its reliability. This impact was studied by performing a sensitivity analysis, in which the grid resistance, $R_{g}$, was changed from $0 \Omega$ to $1 \Omega$, and the $B_{10}$ lifetime of the inverter was calculated accordingly. As shown in Fig. 17, the lifetime of the converter decreases for smaller values of $R_{g}$, such that it changes from 12 years for $R_{g}=1 \Omega$ to 9 years for no grid resistance. This can be justified by the fact that, for smaller values of $R_{g}$, the inverter voltage is smaller, and therefore, a larger current is required to inject the same amount of active power to the grid. It is worth mentioning that the impact of grid reactance is negligible because of the unity power factor assumption, where no reactive power is injected into the grid.

\section{CONCLUSIONS}

In this paper, analytical equations were employed for computationally-efficient electro-thermal modelling of a PhotoVoltaic (PV) inverter. This resulted in significantly faster reliability modelling, which is suitable for iterative design and analysis of large-scale systems. The comparison of the analytical results and simulation results was also made, where both showed a good match. In addition, the reliability

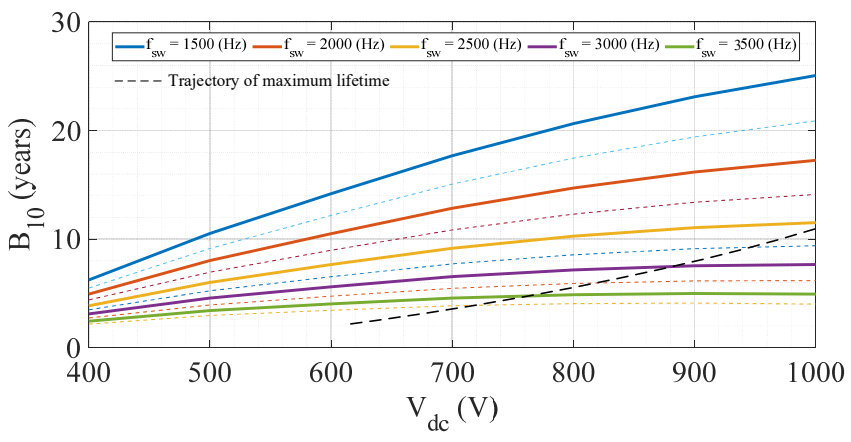

Fig. 15. Variation of lifetime for different values of switching frequency, $f_{s w}$, and DC-link voltage, $V_{d c}$.

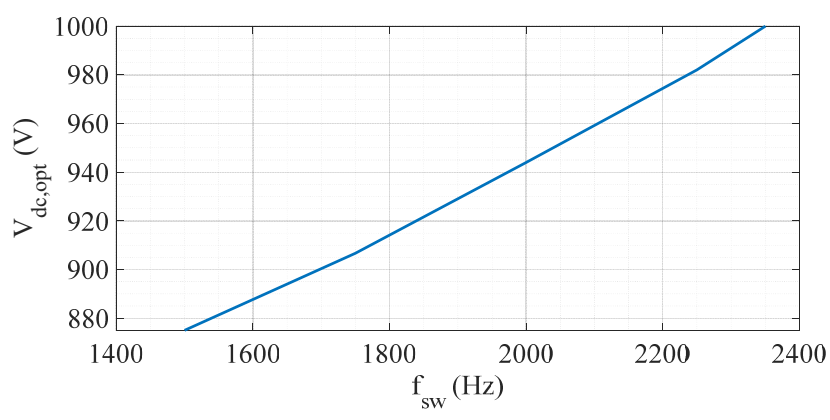

Fig. 16. Variation of DC-link voltage, $V_{d c}$, with switching frequency, $f_{s w}$, on the maximum lifetime trajectory in Fig. 15.

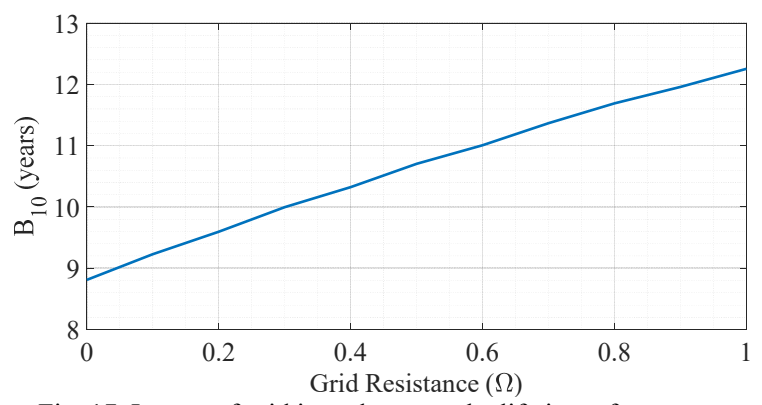

Fig. 17. Impact of grid impedance on the lifetime of converter. 
of a case study PV inverter was analyzed, for which the $B_{10}$ lifetime of 10 years was achieved. By analyzing the data from the reliability model, several solutions were proposed to meet the requirement of $B_{10}=25$ years. To meet this requirement, either the number of PV panels should be changed from 240 to 196 , or $65-$ Watt panels should be replaced with $52-$ Watt ones. Moreover, the relationship of lifetime with switching frequency and DC-link voltage was studied for the case study inverter. Accordingly, it was shown that, with current design and specifications, the lifetime requirement could not be met for switching frequencies higher than $1500 \mathrm{~Hz}$.

\section{REFERENCES}

[1] "International Renewable Energy Agency, (IRENA), Renewable Capacity Statistics, 2020.” [Online]. Available: https://www.irena.org/-

/media/Files/IRENA/Agency/Publication/2020/Mar/IRENA_RE_Cap acity_Statistics_2020.pdf. [Accessed: 12-Sep-2020].

[2] S. Kouro, J. I. Leon, D. Vinnikov and L. G. Franquelo, "Grid-connected photovoltaic systems," IEEE Ind. Electron. Mag., vol. 9, no. 1, pp. 4761, March 2015.

[3] A. Golnas, "PV system reliability: an operator's perspective," IEEE $J$. Photovoltaics, vol. 3, no. 1, pp. 416-421, Jan. 2013.

[4] "Military handbook MIL-HDBK-217F: reliability prediction of electronic equipment," U.S. Dept. Defense, Washington, DC, USA, 1995.

[5] P. Tu, S. Member, S. Yang, and S. Member, "Reliability- and costbased redundancy design for modular multilevel converter," IEEE Trans. Ind. Electron., vol. 66, no. 3, pp. 2333-2342, March 2019.

[6] S. Harb and R. S. Balog, "Reliability of candidate photovoltaic moduleintegrated-inverter (PV-MII) topologies-a usage model approach," IEEE Trans. Power Electron., vol. 28, no. 6, pp. 3019-3027, June 2013.

[7] A. Sangwongwanich, Y. Yang, D. Sera, F. Blaabjerg, and D. Zhou, "On the impacts of PV array sizing on the inverter reliability and lifetime," IEEE Trans. Ind. Appl., vol. 54, no. 4, pp. 3656-3667, Jul. 2018.

[8] T. Dragicevic, P. Wheeler, and F. Blaabjerg, "Artificial intelligence aided automated design for reliability of power electronic systems," IEEE Trans. Power Electron., vol. 34, no. 8, pp. 7161-7171, Aug. 2019.

[9] H. Wang et al., "Transitioning to physics-of-failure as a reliability driver in power electronics," IEEE J. Emerg. Sel. Top. Power Electron., vol. 2, no. 1, pp. 97-114, Mar. 2014.

[10] Y. Zhang, S. Member, H. Wang, S. Member, Z. Wang, and S. Member, "Mission profile-based system-level reliability prediction method for modular multilevel converters," IEEE Trans. Power Electron., vol. 35, no. 7, pp. 6916-6930, July 2020.

[11] S. Peyghami, Z. Wang, and F. Blaabjerg, "A guideline for reliability prediction in power electronic converters," IEEE Trans. Power Electron., pp. 1-1, Oct. 2020.

[12] R. A. P. Franco and F. H. T. Vieira, "Analytical method for extraction of the single-diode model parameters for photovoltaic panels from datasheet data," Electron. Lett., vol. 54, no. 8, pp. 519-521, Apr. 2018.

[13] S. Kolesnik et al., "Solar irradiation independent expression for photovoltaic generator maximum power line," IEEE J. Photovoltaics, vol. 7, no. 5, pp. 1416-1420, Sep. 2017.

[14] A. Laudani et al., "An analytical approach for maximum power point calculation for photovoltaic system," 2017 European Conference on Circuit Theory and Design (ECCTD), Catania, 2017, pp. 1-4

[15] A. Wintrich, N. Ulrich, T. Werner, and T. Reimann, Application Manual Power Semiconductors. Ilmenau, Germany: SEMIKRON International $\mathrm{GmbH}, 2015$.

[16] J. W. Kolar and S. D. Round, "Analytical calculation of the RMS current stress on the DC-link capacitor of voltage-PWM converter systems," in IEE Proceedings - Electric Power Applications, vol. 153, no. 4, pp. 535-543, July 2006.

[17] Effective Solar Products, "High-efficiency photovoltaic module using Silicon Nitride coated multi-crystalline Silicon cells." [Online]. Available: $\quad \mathrm{http}: / / \mathrm{www}$. effectivesolar.com/PDF/bp/BP365.pdf. [Accessed: 12-Sep-2019].

[18] "Infineon AN2019-05: PC and TC Diagrams," Tech. Rep., Infineon Technologies AG, 2019.

[19] A. Albertsen, "Electrolytic Capacitor Lifetime Estimation," Jia Jianghai Eur. GmbH, Krefeld, Germany, 2010. 